\title{
Health-related quality of life is reduced in treated primary hypothyroidism and with lower FT3/FT4-ratio
}

\section{Background}

Despite adequate treatment with LT4 monotherapy, many patients with primary hypothyroidism still report complaints, as this treatment can not exactly imitate the endogenous homeostasis (1).

\section{Aim}

We examined whether the different domains of HR-QOL were affected by the existence of a thyroid disorder and use of LT4 substitution, and whether a lower ratio of FT3 to FT4 could predict lower HR-QOL

\section{Results}

Mean ( \pm SD) age was $51 \pm 13$ years and BMI $26.9 \pm 4.7 \mathrm{~kg} / \mathrm{m}^{2}$ in the LT4 users, vs. $45 \pm 12$ years and $25.8 \pm 4.1 \mathrm{~kg} / \mathrm{m}^{2}$ in the non-users; $90 \%$ of LT4 users were females. We observed considerably higher FT4 and lower FT3 levels in LT4 users, with the FT3/FT4-ratio being $25 \%$ lower in LT4 users, despite similar TSH levels in both groups.

Of the LT4 users, $50 \%$ had a FT3/FT4-ratio which was below the 2.5th percentile of euthyroid individuals. LT4 users reported poorer HR-QOL, the largest reduction was observed in physical functioning, bodily pain, general health and vitality. In the non-LT4-users, those in the lowest tertile of the FT3/FT4-ratio reported a significantly lower HR-QOL in the domains physical functioning and bodily pain compared to participants in the middle and highest tertile.

Table 1. Demographics, thyroid parameters and HR-QOL scores

\begin{tabular}{|l|c|c|c|}
\hline Males / females & Non-LT4-users & LT4-users & P-value \\
\hline Age (years) & $12,707 / 15,876$ & $39 / 328$ & $<0.001$ \\
\hline BMI $\left(\mathrm{kg} / \mathrm{m}^{2}\right)$ & $45 \pm 12$ & $51 \pm 13$ & $<0.001$ \\
\hline TSH & $25.8 \pm 4.1$ & $26.9 \pm 4.7$ & $<0.001$ \\
\hline FT4 & $2.15 \pm 0.88$ & $2.15 \pm 1.12$ & NS \\
\hline FT3 & $15.8 \pm 2.0$ & $18.4 \pm 2.9$ & $<0.001$ \\
\hline FT3/FT4 ratio & $5.3 \pm 0.6$ & $4.6 \pm 0.7$ & $<0.001$ \\
\hline Physical functioning & $9.34 \pm 0.05$ & $0.26 \pm 0.05$ & $<0.001$ \\
\hline Bodily pain & $90(78-100)$ & $90(80-95)$ & $<0.001$ \\
\hline Vitality & $84(72-88)$ & $80(67-100)$ & $<0.001$ \\
\hline General health & $75(65-85)$ & $70(55-80)$ & \\
\hline
\end{tabular}

Data as $n$, meanSD, or median (IQR)

\section{Major findings}

Patients treated with LT4 monotherapy for primary hypothyroidism report lower HR-QOL compared to non-users and healthy control subjects. In subjects not using LT4, a lower FT3/FT4-ratio was associated with more impairments in some domains of HR-QOL.

\section{References}

1. Gullo D, et al. PLOS One 2011; 2. Stolk RP, et al. Eur J Epid 2008; 3. Hays RD, et al. The Psychological Corporation 1998.

\section{Methods}

A total of 28,950 Wsetern European participants from the population-based Life Lines Cohort Study (2), with normal thyroid stimulating hormone (TSH) values (0.4-4.5 $\mathrm{mU} / \mathrm{I})$, were evaluated; 367 of them used LT4 monotherapy. TSH, free thyroxine (FT4) and free triiodothyronine (FT3) were measured with electrochemiluminescent immunoassay on the Roche Modular E170 Analyzer. HR-QOL was assessed with the Short Form-36 questionnaire (3). Scores in the individual HR-QOL domains range between 0-100 (best), and we calculated the number of participants with an abnormal score. Their scores were compared with those in the general population (non-LT4-users), but also with a healthy group of participants without relevant co-morbidity or medication use for any medical reason.

Table 2. Health-related quality of life in LT4 users compared to non-users, and to healthy control subjects without co-morbidity

\begin{tabular}{|lccc|}
\hline Healthy controls w.o. med's, N & 8,454 & 7,832 & 16,286 \\
\hline Physical functioning < 85 (\%) & 7.9 & 12.8 & 10.2 \\
\hline Bodily pain < 70 (\%) & 15.2 & 21.9 & 18.4 \\
\hline General health < 65 (\%) & 18.3 & 16.7 & 17.5 \\
\hline Vitality < 60 (\%) & 18.4 & 23.8 & 21.0 \\
\hline & & & \\
\hline Non-LT4-users, N & 12,707 & 15,876 & 28,583 \\
\hline Physical functioning < 85 (\%) & 11.8 & 18.5 & 15.5 \\
\hline Bodily pain < 70 (\%) & 18.6 & 27.6 & 23.6 \\
\hline General health <65 (\%) & 23.0 & 22.6 & 22.8 \\
\hline Vitality < 60 (\%) & 20.4 & 27.8 & 24.6 \\
\hline Subjects using LT4, N & 39 & 328 & 367 \\
\hline Physical functioning < 85 (\%) & 18.4 & 33.5 & 32.0 \\
\hline Bodily pain < 70 (\%) & 18.4 & 39.0 & 36.8 \\
\hline General health < 65 (\%) & 28.9 & 36.6 & 35.8 \\
\hline Vitality < 60 (\%) & 36.8 & 39.6 & 39.3 \\
\hline
\end{tabular}

Table 3. Relevant health-related quality of life domains according to the FT3/FT4 ratio (tertiles) in non-LT4-users

\begin{tabular}{|l|c|c|c|c|}
\hline & Tertile 1 & Tertile 2 & Tertile 3 & P-value \\
\hline Physical functioning <85 (\%) & 16.9 & 15.1 & 14.6 & $<0.001$ \\
\hline Bodily pain $<70(\%)$ & 24.1 & 23.3 & 22.7 & 0.007 \\
\hline General health $<65(\%)$ & 22.2 & 22.2 & 23.9 & NS \\
\hline
\end{tabular}

*Information: bwo@umcg.nl

\section{Healthy Ageing}

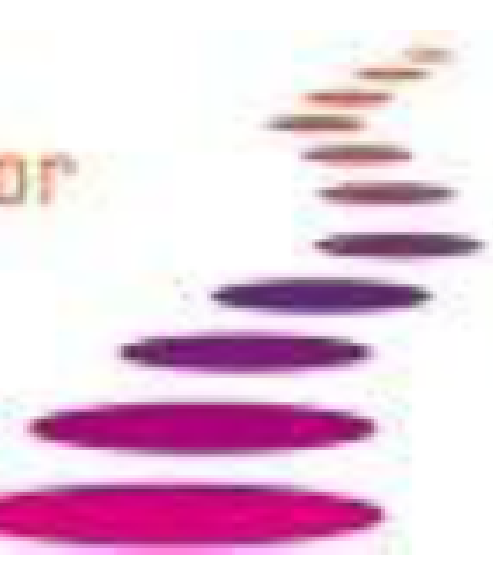

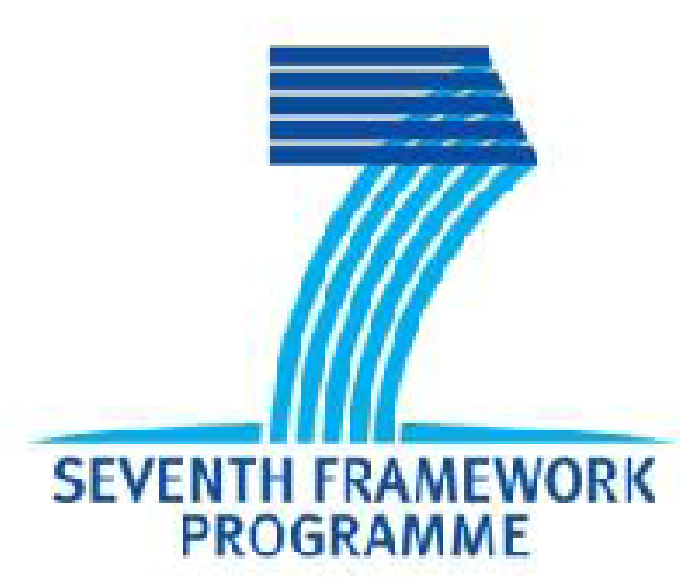

